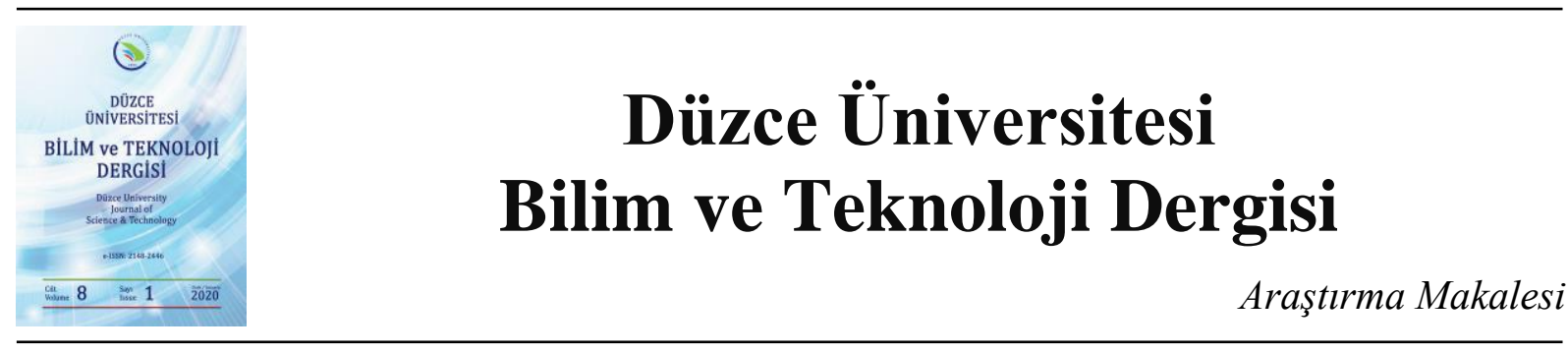

\section{Çukurova Havzası'nda Uyarlanabilir Ağ Tabanlı Bulanık Çıkarım Sistemi Kullanılarak Kuraklığın Tahmini}

\author{
(D) Özlem TERZİ ${ }^{\mathrm{a}, *}$, (D) Ayșegül TERZİ ${ }^{\mathrm{b}}$ \\ ${ }^{a}$ İnşaat Mühendisliği Bölümü, Teknoloji Fakültesi, Isparta Uygulamalı Bilimler Üniversitesi, Isparta, TÜRKIYE \\ ${ }^{b}$ Yapı Eğitimi Anabilim Dalı, Fen Bilimleri Enstitüsü, Süleyman Demirel Üniversitesi, Isparta, TÜRKIYE \\ * Sorumlu yazarin e-posta adresi: ozlemterzi@isparta.edu.tr
}

DOI: 10.29130/dubited.599485

\begin{abstract}
ÖZET
Yağış miktarındaki azalmalar ve sıcaklıktaki yükselmeler kuraklığın oluşumundaki önemli faktörlerdendir. Kuraklık gerek insanlar için gerekse ekolojik denge için birçok olumsuz etkiyi de beraberinde getirmektedir. Bitki örtüsünün azalması, tarım ürünlerinden elde edilen verimin düşmesi ve temiz su kaynaklarının azalması kuraklı̆ğın olumsuz etkilerindendir. Bu çalışmada, kuraklığın hissedildiği bölgelerden biri olan Çukurova Havzası'nda kuraklık tahmini yapılmıştır. Bunun için havzada bulunan farklı meteoroloji istasyonlarına ait aylık ortalama yağış verileri kullanılarak Standart Yağış İndisi (SYİ) yöntemiyle kuraklık analizi yapılmıştır. Analiz sonucunda elde edilen SYİ değerleri kullanılarak Uyarlanabilir Ağ Tabanlı Bulanık Çıkarım Sistemi (ANFIS) yöntemi ile modeller geliştirilmiş̧ir. Geliştirilen modeller içerisinde en uygun sonuçlar 9- aylık SYİ değerleri kullanılarak geliştirilen ANFIS modelinde elde edilmiştir ve bu modelin kullanılabilir olduğu görülmüştür.
\end{abstract}

Anahtar Kelimeler: Kuraklık, Standart Yă̆ış İndisi, ANFIS, Çukurova Havzası

\section{Drought Estimation by using Adaptive Network Based Fuzzy Inference System in Çukurova Basin}

\begin{abstract}
Decreases in the amount of precipitation and increases in temperature values are important factors in the formation of drought. Drought has many negative effects for both human and ecological balance. The decrease of vegetation, the yield obtained from agricultural products and clean water resources are among the negative effects of drought. In this study, drought estimation was made in Çukurova Basin, which is one of the regions of drought. For this purpose, drought analysis was performed by the Standard Precipitation Index (SPI) method using the monthly average precipitation data of different meteorological stations in the basin. Models were developed with Adaptive Neuro Fuzzy Inference System (ANFIS) by using the SPI values obtained from the drought analysis. Among the developed models, the best results were obtained in the ANFIS model developed using the 9-month SPI values and it was shown that the developed model was usable.
\end{abstract}

Keywords: Drought, Standardized Precipitation Index, ANFIS, Çukurova Basin 


\section{GIRIS}

Kuraklık en genel tanımı ile "yağışların, kaydedilen normal seviyelerinin önemli ölçüde altına düşmesi sonucu, arazi ve su kaynaklarının olumsuz etkilenmesine ve buna bağlı olarak hidrolojik dengenin bozulmasına sebep olan doğal olay" şeklinde ifade edilebilir [1]. Ülkemizin yarı kurak iklim kuşağında yer alması sebebiyle kuraklık olayları yaygın olarak karşımıza çıkmaktadır. Meteorolojik kuraklığın süresinin uzunluğu, ülkemizde bulunan tarım alanlarının yeterli biçimde sulanmasında problemler yaşanmasına ve buna bağlı olarak tarımsal üretimde ciddi düzeylerde düşüşe, yeryüzü ve yer altı sularında azalmaya, bitki örtüsünün gelişmesi için gerekli olan nem miktarının karşılanamamasına yol açmaktadır. Bazı dönemlerde örneğin 1973, 1989, 1990, 1993, 1998, 2001 yıllarında kaydedilen verilere göre yoğun kuraklıklar gözlenmiş ve özellikle 1980 yılının sonrasında da sıcaklıklarda artışlar tespit edilmiştir. Ülkemizde kişi başına düşen yıllık su miktarı $1519 \mathrm{~m}^{3}$ olduğu için su kaynakları bakımından zengin bir ülke olmadığımız düşünülmektedir [2]. Bu durumda ülkemizde zaten varolan hidrolojik kuraklığın, nüfus artışı ile daha ciddi boyutlara taşınabilmesi tehdidi oluşmaktadır. Dolayısıyla, kuraklığın ülkemiz ve dünya üzerindeki olumsuz etkileri dikkate alındığında konuyla ilgili literatürde çeşitli çalışmalar bulunduğu görülmüştür [3-7]. Tanoğlu [8] yalnızca yağış haritaları ve yağışların yıl içinde dağılışları, mevsimlere ve aylara göre dağılışını gösteren grafikler ile kuraklık hakkında yeterli fikir elde edilemeyeceğinden yağışın yanında sıcaklığında dikkate alınması gerekliliğine değinmiştir. De Martonne formülünü kullanarak Türkiye'nin kuraklık haritasını hazırlamıştır. Köse ve Dorum [9] kuraklık değişkenlerinin olasılık dağılımlarını elde etmek için Orta Anadolu Kapalı Havzası'nda yağış verilerini incelemiştir. Kararlılık ve rastgelelik analizleri ile Ki-Kare ve Kolmogorov-Smirnov analizlerini sırası ile uygulayarak analizlerin sonucunda kuraklık olaylarının düzenli biçimde birbirlerini takip etmediği sonucuna varmıştır. Küçükyaman [10] Kovada Gölü'nün hidrolojik ve meteorolojik kuraklık analizlerini yapmak için bölgenin yağış verilerini kullanmıştır. Standart yağış indisi (SYİ) değerlerini hesaplayarak uyarlanabilir ağ tabanlı bulanık çıkarım sistemi (ANFIS) ve yapay sinir ağları (YSA) yöntemleri ile kuraklığı modellemiştir. Hidrolojik kuraklık analizinde ise göl, hacim ve seviye verileri ile oluşturduğu grafikleri inceleyerek göl seviyesinde azalmalar saptamıştır. Bu çalışma ile seviye düşüşlerinin temel sebebinin yağış azalmaları olduğunu belirlemiştir. Bacanlı [11] Akdeniz ve Ege bölgeleri için Palmer Kuraklık İndisi ve SYİ ile kuraklık değerlerini belirlemiştir. Daha sonra YSA ve bulanık mantık yöntemleri ile kuraklık modelleri geliştirmiştir. Bölgede yaz aylarının yanında kış aylarında da yağışlarda azalmalara bağlı kurak dönemler tespit etmiştir.

Literatür incelendiğinde, Çukurova Havzası'nın tümünde ANFIS modeli kullanılarak kuraklık tahmin çalışmasına rastlanmamıştır. Bu çalışmada, ülkemizin verimli tarım arazilerinin bulunduğu Çukurova Havzası'nda belirlenen 11 meteoroloji gözlem istasyonunun verileri kullanılarak kuraklık analizi yapılmıştır. Kuraklık analizi için bu istasyonların 50 yıllık yağış verileri kullanılarak 3-, 6-, 9- ve 12aylık SYİ değerleri hesaplanmıştır. Hesaplanan SYİ değerleri ile ANFIS kullanılarak kuraklık modelleri geliştirilmiştir.

\section{MATERYAL VE YÖNTEM}

\section{A. ÇALIŞMA BÖLGESİ VE VERILLER}

Çukurova Havzası 3150 km² yüz ölçümü ile Akdeniz Bölgesi'nin doğusunda yer alan ülkemizin en önemli ovalarındandır. Şekil 1'de görüldüğü gibi havzanın doğu bölgesinde Ceyhan Nehri, batısında Seyhan Nehri ile Tarsus Çayı yer almaktadır. Akdeniz ile Toros Dağları arasında yer alan Çukurova, Seyhan ve Ceyhan Nehri ile Tarsus Çayı'nın taşıdığı alüvyonların bir araya gelmesi ile oluşan bir delta ovasıdır. Çukurova'nın büyük bölümünde tarım yapılması nedeniyle ihtiyaç duyulan sulamada Seyhan Nehri üzerinde Seyhan Barajı, Tarsus Çayı üzerinde ise Kadıncık-1 ve Kadıncık-2 Barajları havzanın sulama ihtiyacını büyük ölçüde karşılamaktadır. Havzanın en büyük sulama kaynaklarından biri olan Seyhan Nehri 560 km uzunluğu ile Akdeniz'e dökülen rrmaklar içinde en uzun olanıdır. Havzanın doğusunda yer alan Ceyhan Nehri ise Çukurova'da geniş bir delta oluşturarak İskenderun Körfezi'ne dökülür. 509 km uzunluğundaki Ceyhan Nehri'nin Kasım ve Aralık aylarındaki debisi $380 \mathrm{~m}^{3} / \mathrm{sn}$ 'ye kadar ulaşır. Bu seviyeler Ocak ayında azaldıktan sonra Şubat ayında tekrar yükselişe geçmektedir [12]. 
Çukurova Havzası'nda özellikle yaz aylarında görülen yağış azlığı sebebiyle dönem dönem kuraklıklar yaşanmaktadır. Havzanın yıllık ortalama sıcaklığı $19,2{ }^{\circ} \mathrm{C}$ 'dir. Yaz aylarında sıcaklıklar $40{ }^{\circ} \mathrm{C}$ 'nin üzerine çıkarken yıllık ortalama yağış miktarı ise 600-700 mm'dir.

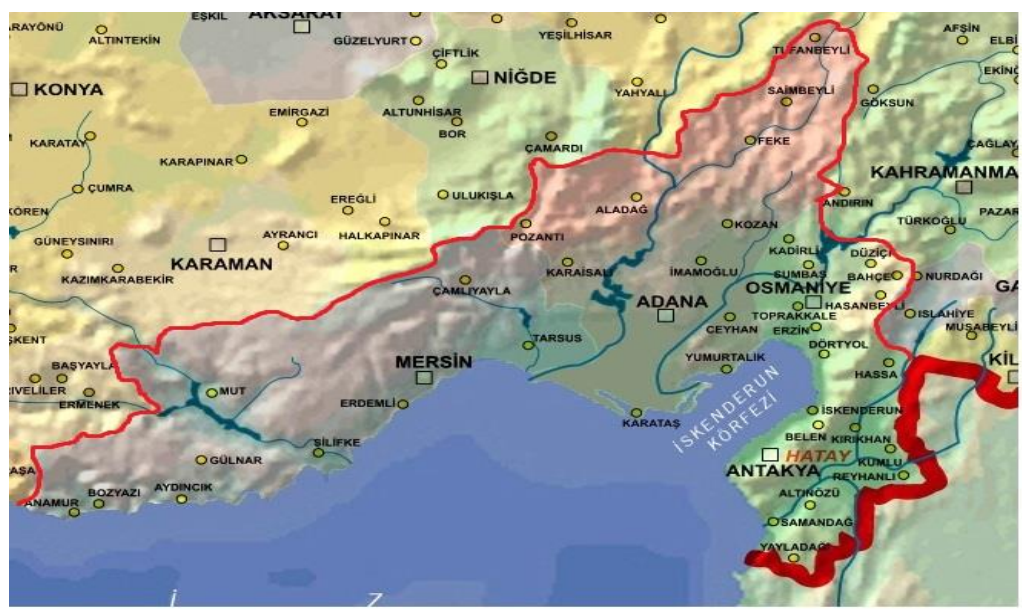

Şekil 1. Çukurova Havzası

Araştırmada, Çukurova Bölgesi’nde yer alan ve Devlet Meteoroloji İşleri Genel Müdürlüğü (DMİ) tarafından işletilen Mersin, Karaisalı, Karataş, Kilis, Yumurtalık, Kozan, Karapınar, Göksun, Samandağ, Dörtyol ve Erdemli meteoroloji gözlem istasyonlarının 1965-2014 yılları arası aylık yağış değerleri kullanılmıştır. Tablo 1'de çalışmada kullanılan meteoroloji gözlem istasyonlarının yıllık toplam yağış istatistikleri verilmiştir.

Tablo 1. İstasyonların 1965-2014 yılları arası yıllık toplam yağış istatistikleri

\begin{tabular}{cccccc}
\hline İstasyon No & İstasyon Adı & $\begin{array}{c}\text { Ortalama } \\
(\mathrm{mm})\end{array}$ & $\begin{array}{c}\text { Maksimum } \\
(\mathrm{mm})\end{array}$ & $\begin{array}{c}\text { Minimum } \\
(\mathrm{mm})\end{array}$ & Standart Sapma \\
\hline 17340 & Mersin & 594,44 & 1033,8 & 278,8 & 65,45 \\
\hline 17262 & Kilis & 491,00 & 814,4 & 290,7 & 43,76 \\
\hline 17979 & Yumurtalık & 793,38 & 1180,3 & 428,0 & 70,36 \\
\hline 17908 & Kozan & 827,60 & 1297,4 & 547,6 & 58,02 \\
\hline 17902 & Karapınar & 281,80 & 412,9 & 171,6 & 20,98 \\
\hline 17936 & Karaisalı & 872,09 & 1262,4 & 393,2 & 77,98 \\
\hline 17866 & Göksun & 586,81 & 869,2 & 181,4 & 45,55 \\
\hline 17986 & Samandağ & 900,41 & 1299,8 & 466,8 & 74,78 \\
\hline 17981 & Karataş & 773,51 & 1269,6 & 366,3 & 81,75 \\
\hline 17962 & Dörtyol & 930,52 & 1334,8 & 620,0 & 62,68 \\
\hline 17958 & Erdemli & 589,33 & 965,7 & 242,6 & 65,49 \\
\hline
\end{tabular}

\section{B. STANDART YAĞIŞ İNDİSi}

Standart yağış indisi (SYİ), 1993 yılında McKee vd. [13] tarafından kuraklığı tanımlamak için geliştirilmiş bir yöntemdir. SYİ değeri yağış miktarından ortalama yağış miktarı çıkarılarak elde edilen değerin standart sapmaya bölünmesi ile elde edilir. SYİ ile belli zaman dilimlerinde belli bir bölgede kuraklık değişimleri incelenebilirken kuraklık tahminleri de yapılabilmektedir. SYİ, meteorolojik kuraklık çalışmalarında yaygın şekilde kullanılan bir yöntemdir. SYİ değeri elde edilirken Eşt. 1 uygulanır.

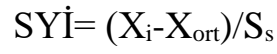


SYİ : Standart Yağış İndisi

$\mathrm{X}_{\mathrm{i}} \quad$ : Yağış miktarı

$\mathrm{X}_{\mathrm{ort}} \quad$ : Ortalama yăğş miktarı

$\mathrm{S}_{\mathrm{s}} \quad$ : Standart sapma değeri

SYİ ile 3-, 6-, 9-, 12- ay veya 24-, 48- ay gibi daha uzun zaman dilimleri için analizler yapılarak kuraklık kategorileri ve kuraklık yüzdelerinin belirlenmesinde büyük kolaylıklar sağlanmaktadır [14]. SYİ değerleri belli aralıklarla Tablo 2'de görüldüğü gibi kategorize edilmektedir.

Tablo 2. Kuraklık Kategorileri [15]

\begin{tabular}{cc}
\hline SYİ değeri & Kuraklık Kategorisi \\
\hline 0,0 ile $-0,99$ & Hafif \\
$-1,0$ ile $-1,49$ & Orta \\
$-1,5$ ile $-1,99$ & Şiddetli \\
$-2,00$ ve daha az & Çok Şiddetli \\
\hline
\end{tabular}

Yağış ile ilgili yapılan çalışmalarda genellikle aylık toplam yağışlar kullanılmaktadır. SYİ değerleri sadece istasyonlardan elde edilen yağış değerleri kullanılarak hesaplandığı için pratik ve sık kullanılan bir yöntemdir. Bu yöntem ile istediğimiz zaman aralığındaki kurak dönemler ve bu dönemlerin şiddeti belirlenebilmektedir. SYİ değerlerinin 0,00 ile $-0,99$ arasında değerler alması belirlenen zaman aralığında hafif kuraklığı; $-1,00$ ile $-1,49$ arasında değer alması orta düzeyde kuraklığı; $-1,5$ ile $-1,99$ arasında değerler alması şiddetli kuraklığı ve $-2,00$ 'den daha düşük değerler alması ise çok şiddetli kuraklı̆̆ göstermektedir.

\section{UYARLANABİLİR AĞ TABANLI BULANIK ÇIKARIM SİSTEMİ}

1997 yılında Jang vd. [16] tarafından geliştirilen, uyarlanabilir ă̆ tabanlı bulanık çıkarım sistemi (Adaptive-Network Based Fuzzy Inference Systems - ANFIS), yapay sinir ağları (YSA) ile bulanık mantığın bir arada kullanıldığı bir yapay zeka yöntemidir. ANFIS'in genel yapısı girdi ve çıktı kombinasyonlarından oluşmaktadır. ANFIS, yapay sinir hücreleri ile öğrenme becerisine sahip Sugeno tipi bulanık sistemler için grafiksel bir ağ yapısından oluşmaktadır. Ağ yapısı özel fonksiyonları olan tabakalardan ve düğüm noktalarından meydana gelmektedir [17].

Bulanık sistemin ortaya çıkarabileceği bir takım sakıncaları kısmen ortadan kaldırabilmek için TakagiSugeno ve Sugeno-Kank tarafından geliştirilen Takagi Sugeno-Kank (TSK) bulanık sistemi denilen sistem kullanılır. Bu sistemde veri tabanındaki girdiler birer sayı, bulanık kural ve çıkarım motorunun çalışması sonunda elde edilen çıktılar ise girdilerin bir fonksiyonu şeklinde oluşmaktadır [10].

ANFIS model melez öğrenme (Hybrid learning) algoritması ile Sugeno tipi bulanık çıkarım sistemini bir araya getirerek adaptif ağlar ve doğrudan bağlanmış düğümlerden meydana gelmektedir. ANFIS model içinde bulunan her bir düğüm ve düğümlerin arasındaki bağlantılar bir işlemi ifade etmektedir. $\mathrm{Bu}$ dügümlerin bir kısmı veya hepsi adaptif (uyumlu) yapıda olabilmekte ve bu düğümlerde yer alan parametreler hatayı en aza indirecek şekilde değişkenlerden oluşmaktadır [18].

Birinci derece Sugeno tip bulanık model ve bu modeli tanımlayan ANFIS modelleri 5 ana tabakadan meydana gelir. Şekil 2'de görülen bu tabakaların her birinde nöronlar bulunmakta ve hepsi ayrı işlevleri yerine getirmektedir. 


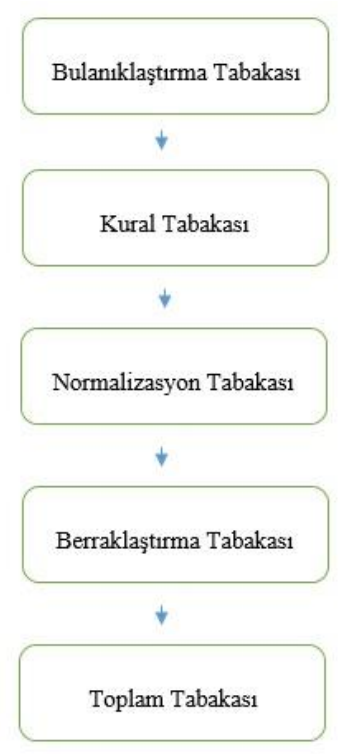

Şekil 2. ANFIS model tabakalart [19]

İlk tabaka bulanıklaştırma olarak bilinen model girdilerini bulanık kümelere ayrıştıran tabakadır. Kural tabakasında, bulanıklaştırma tabakasında kümelere ayrılan model girdileri için Sugeno bulanık mantık çıkarım sistemine göre kurallar oluşturulmaktadır. Normalizasyon tabakasındaki her düğüm, bir önceki tabakadan gelen tüm düğümleri giriş değeri olarak kabul ederek kuralların normalleştirilmiş değerini hesaplamaktadır. Berraklaştırma tabakasında bulunan düğümlerde verilen kuralların ağırlıklandırılmış sonuç değerleri hesaplanmaktadır. Son olarak toplam tabakasında sadece bir dügüm vardır ve bu tabakada berraklaştırma tabakasındaki her bir dügümün çıkış değeri toplanarak ANFIS sisteminin gerçek değeri elde edilmektedir [19].

\section{ARASTIRMA BULGULARI VE TARTISSMA}

Bu çalışmada, Çukurova Bölgesi'nde yer alan ve DMİ tarafından işletilen Mersin, Karaisalı, Karataş, Kilis, Yumurtalık, Kozan, Karapınar, Göksun, Samandağ, Dörtyol, Erdemli olmak üzere 11 adet meteoroloji gözlem istasyonunun 1965-2014 yılları arası aylık yağış değerleri kullanılarak SYİ ile meteorolojik kuraklık analizi yapılmıştır. Daha sonra, 3-, 6-, 9- ve 12- aylık SYİ değerleri kullanılarak ANFIS modelleri geliştirilmiştir.

İlk olarak, Çukurova Havzası'nda bulunan istasyonlardan alınan yağış verileri ile homojenlik analizleri yapılmıştır. $\mathrm{Bu}$ analizlerde çift toplam yağış eğrileri oluşturularak doğru eğimleri incelenmiş ve yağış verilerinin homojen olduğu görülmüştür. Yağış verileri kullanılarak hesaplanan 3-, 6-, 9- ve 12- aylık SYİ değerleri ile belirlenen zaman aralıklarında görülen kurak dönemler, hangi kuraklık kategorisinde yer aldığı ve her istasyonun ayrı ayrı kurak olma frekansları belirlenmiştir.

Kuraklık kategori olasılıkları belirlenirken her istasyonun 3-, 6-, 9- ve 12- aylık zaman aralıkları için kuraklık kategorilerinde bulunan yüzde dağılımları hesaplanmıştır. Kuraklık kategorisinin hesaplanan zaman dilimi içinde tekrarlanma sayısı serinin toplam eleman sayısına bölünerek sonuç 100 ile çarpılmış ve kuraklık kategorisinin bulunduğu periyotta görülme yüzdesi hesaplanmıştır.

Bölgede bulunan 11 adet meteoroloji istasyonuna ait SYİ değerleri kullanılarak 3-, 6-, 9- ve 12- aylık periyotlar için hesaplanan kuraklık kategori olasılıkları yüzde olarak Tablo 3 'te verilmişstir. 
Tablo 3. Kuraklık kategorileri olasılıkları (\%)

\begin{tabular}{|c|c|c|c|c|}
\hline Kuraklık Kategorisi & Hafif & Orta & Şiddetli & Çok Şiddetli \\
\hline \multicolumn{5}{|l|}{ Samandă̆ } \\
\hline 3 Aylik & 44,0 & 11,3 & 0,0 & 0,0 \\
\hline 6 Aylık & 48,8 & 8,16 & 0,5 & 0,0 \\
\hline 9 Aylık & 48,1 & 10,1 & 0,3 & 0,0 \\
\hline 12 Aylik & 45,6 & 11,3 & 0,0 & 0,0 \\
\hline \multicolumn{5}{|l|}{ Erdemli } \\
\hline 3 Aylık & 45,5 & 10,6 & 0,0 & 0,0 \\
\hline 6 Aylık & 56,2 & 5,6 & 0,1 & 0,0 \\
\hline 9 Aylık & 58,9 & 4,5 & 0,0 & 0,0 \\
\hline 12 Aylık & 57,8 & 5,5 & 0,0 & 0,0 \\
\hline \multicolumn{5}{|l|}{ Göksun } \\
\hline 3 Aylık & 39,6 & 13,5 & 0,0 & 0,0 \\
\hline 6 Aylık & 47,5 & 7,8 & 1,3 & 0,0 \\
\hline 9 Aylık & 45,4 & 11,2 & 0,5 & 0,0 \\
\hline 12 Aylık & 42,1 & 13,6 & 0,1 & 0,0 \\
\hline \multicolumn{5}{|l|}{ Karaisalı } \\
\hline 3 Aylık & 42,0 & 12,5 & 0,0 & 0,0 \\
\hline 6 Aylık & 50,3 & 9,0 & 0,6 & 0,0 \\
\hline 9 Aylik & 43,6 & 8,5 & 0,0 & 0,0 \\
\hline 12 Aylik & 49,0 & 10,1 & 0,5 & 0,0 \\
\hline \multicolumn{5}{|l|}{ Karapınar } \\
\hline 3 Aylık & 44,3 & 11,3 & 0,0 & 0,0 \\
\hline 6 Aylık & 49,6 & 7,0 & 1,3 & 0,0 \\
\hline 9 Aylık & 42,7 & 13,1 & 0,8 & 0,0 \\
\hline 12 Aylık & 38,6 & 15,0 & 0,8 & 0,0 \\
\hline \multicolumn{5}{|l|}{ Yumurtalık } \\
\hline 3 Aylik & 43,6 & 11,5 & 0,0 & 0,0 \\
\hline 6 Aylık & 50,0 & 8,3 & 0,6 & 0,0 \\
\hline 9 Aylik & 51,0 & 9,1 & 0,0 & 0,0 \\
\hline 12 Aylık & 50,6 & 9,9 & 0,0 & 0,0 \\
\hline \multicolumn{5}{|l|}{ Kilis } \\
\hline 3 Aylık & 47,0 & 9,8 & 0,0 & 0,0 \\
\hline 6 Aylık & 49,3 & 7,3 & 2,1 & 0,1 \\
\hline 9 Aylık & 45,9 & 10,6 & 0,1 & 0,0 \\
\hline 12 Aylık & 44,0 & 12,0 & 0,0 & 0,0 \\
\hline \multicolumn{5}{|l|}{ Kozan } \\
\hline 3 Aylık & 41,6 & 12,5 & 0,0 & 0,0 \\
\hline 6 Aylık & 50,0 & 9,1 & 0,8 & 0,0 \\
\hline 9 Aylik & 47,1 & 11,1 & 0,8 & 0,0 \\
\hline 12 Aylik & 43,5 & 13,3 & 0,5 & 0,0 \\
\hline \multicolumn{5}{|l|}{ Mersin } \\
\hline 3 Aylık & 42,6 & 12,0 & 0,0 & 0,0 \\
\hline 6 Aylık & 53,5 & 6,3 & 0,5 & 0,0 \\
\hline 9 Aylik & 59,2 & 4,4 & 0,3 & 0,0 \\
\hline 12 Aylik & 52,8 & 7,5 & 0,0 & 0,0 \\
\hline \multicolumn{5}{|l|}{ Dörtyol } \\
\hline 3 Aylik & 42,6 & 12,0 & 0,0 & 0,0 \\
\hline 6 Aylık & 42,8 & 9,5 & 0,0 & 0,0 \\
\hline 9 Aylık & 43,2 & 12,4 & 0,0 & 0,1 \\
\hline 12 Aylik & 43,8 & 12,8 & 0,8 & 0,0 \\
\hline \multicolumn{5}{|l|}{ Karataş } \\
\hline 3 Aylik & 46,1 & 10,3 & 0,0 & 0,0 \\
\hline 6 Aylık & 52,6 & 8,5 & 0,0 & 0,0 \\
\hline 9 Aylık & 58,4 & 4,2 & 0,3 & 0,0 \\
\hline 12 Aylık & 53,5 & 7,0 & 0,0 & 0,0 \\
\hline
\end{tabular}


Tablo 3'te bulunan 3- aylık periyotlar incelendiğinde 3- aylık periyotlarda hafif kurak dönemlerin yoğunlukta olduğu görülmektedir. Hafif kuraklığın en fazla olduğu istasyon $\% 47$ oran ile Kilis, en düşük olduğu istasyon ise \%39,6 ile Göksun istasyonudur. Orta şiddette kurak dönemler ise 3- aylık periyotlarda \%9,8 ile \%13,5 arasında değerler almıştır. Şiddetli ve çok şiddetli dönemlere 3- aylık periyotlarda rastlanmamıştır. Bölge genelinde 3- aylık periyotlar ve Şekil 3 birlikte incelendiğinde en düşük kuraklık değeri 1979 yılında Karaisalı istasyonunda -1,16 SYİ değeri ile hissedilmiştir.

6- aylık periyotlarda hafif kuraklık 3 aylık periyotlara göre daha yüksek orandadır. $\% 42,8$ ile $\% 56,2$ arasında değerler izlenmiştir. Bu dönemde hafif kuraklığın en yoğun hissedildiği istasyon \%56,2 oranı ile Erdemli istasyonudur.

Şiddetli kuraklık en fazla \%2.1 değeri ile Kilis istasyonunda gözlemlenmiştir. Kilis istasyonunun 6aylık periyotlarda SYİ değerleri incelendiğinde 1967 yılında -2.01 değeri ile en düşük seviyeye inmiştir. Yine çok şiddetli kurak dönemler 6- aylık periyotlarda diğer istasyonlarda görülmezken 1967 yılında kaydedilen veriler ile Kilis’te rastlanmıştır.

9- aylık periyotta hafif kuraklık değerleri $\% 59,2$ ile Mersin istasyonunda en yüksek değerde gözlenmiştir. Mersin istasyonunda 3-, 6-, 9- ve 12- aylık tüm dönemlerde hafif kurak dönemlerin belirgin olarak yaşandığg görülmüş̧ür. 9- aylık periyotta orta kurak dönemler \%4,3 - \%13,1 arasında değerler almıştır. Orta kurak dönemlerin en yoğun yaşandığı istasyon ise Karapınar istasyonudur. Şiddetli kurak dönemlere 9- aylık periyotta Dörtyol, Yumurtalık, Karaisalı ve Erdemli'de rastlanmazken diğer yedi istasyonda da düşük oranlarda hissedilmiştir.

9- aylık periyotlarda en yoğun kuraklık 2010 yılında -2,09 SYİ değeri ile Karataş istasyonunda gözlemlenmiştir. Çok şiddetli kuraklığa ise yine 2010 yılında gözlenen yağı̧ verilerine istinaden \% 0,1 oranında Dörtyol istasyonunda rastlanmıştır.

12- aylık periyotlarda \%38,6 ile hafif kuraklığın en düşük değeri Karapınar istasyonunda görülmüştür. En yükssek değer ise \%57,8 ile Erdemli istasyonundadır. Orta kuraklık değerleri Karapınar istasyonunda $\% 15$ 'lere kadar ulaşmıştır. Karapınar ve Dörtyol istasyonlarında çok şiddetli kurak dönemler görülmezken şiddetli kurak dönemler $\% 0,8$ ile en yüksek değerini bu istasyonlarda almıştır. Şiddetli kurak dönemler Samandağ, Erdemli, Yumurtalık, Kilis, Mersin, Karataş istasyonlarında görülmemiştir.

Havza genelinde 12- aylık periyotlar incelendiğinde 1976-1983 arası ve 2002-2005 yılları aras1 kuraklığın en yoğun olduğu dönemler olarak belirlenmiştir. 12- aylık periyotlarda çok şiddetli dönemlere rastlanmamıştır.

Karaisalı istasyonuna ait SYİ grafikleri Şekil 3'de verilmiştir. Şekil 3 incelendiğinde 3-aylık periyotta en kurak ay olan 1979 yılının Nisan ayında -1.16 ile en düşük SYİ değeri görülmüsşür. En nemli ay ise 1965 Ağustos ay1, SYİ değeri 1,15'tir. 6- aylık periyotta ise -1.67 olan en düşük SYİ değeri 1980'nin Haziran ayında belirlenmiştir. En yüksek SYİ değeri ise 2012 yılının Ocak ayında 2,02'dir. 9- aylık periyota bakıldığında kuraklığın en yoğun olduğu 1995 yılının Eylül ayında en düşük SYİ değeri 1,76'dır. 2001 yılının Aralık ayı en nemli aydır ve en yüksek SYİ değeri 2,57'dir. 12-aylık periyotta ise kuraklığın en yoğun görüldüğü ay 2005 yılının Temmuz ayıdır ve Temmuz ayında -1,60 ile en düşük SYI değeri belirlenmiştir. Kuraklığın en az hissedildiği ay ise 2001 yılının Aralık ayı olmakla birlikte SYİ değeri 3,02'dir. 

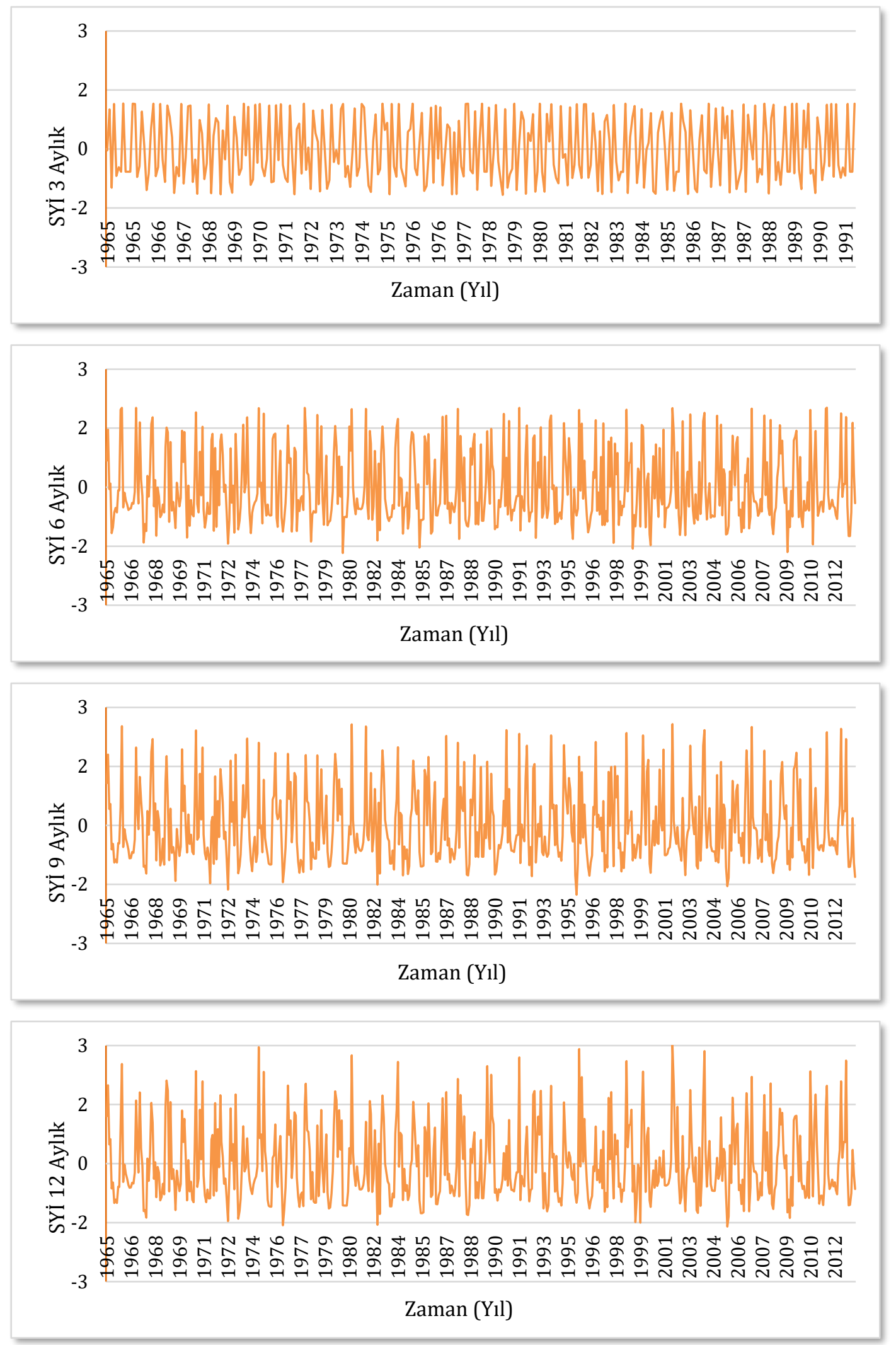

Şekil 3. Karaisalı istasyonu SYİ dĕgerler

Çalışmanın ikinci kısmında, 1965-2014 yılları arasındaki yağış verileri ile hesaplanan SYİ değerleri girdi ve çıktı parametreleri olarak kullanılıp 3-, 6-, 9- ve 12- aylık dönemler için ANFIS kuraklık modelleri geliştirilmiştir. ANFIS kuraklık modeli geliştirilirken havzanın merkezinde ve tarım açısından 
önemli olan bölgede bulunan Karaisalı istasyonu çıktı olarak belirlenmiştir. 10 adet istasyonun SYİ değerleri girdi olarak kullanılarak farklı kombinasyonlar denenmiştir.

ANFIS modelleri oluşturulurken 1965 yılından 2014 yılına kadar olan 50 yıllık süre için hesaplanan SYİ değerlerinden ilk \%80'lik kısmı eğitim veri seti, kalan \%20'si ise test veri seti olarak kullanılmıştır. ANFIS modellerinin uygunluğu determinasyon katsayısı $\left(\mathrm{R}^{2}\right)$ ve ortalama karesel hata $(\mathrm{OKH})$ değerlerine göre değerlendirilmiştir. $\mathrm{R}^{2}$ ve $\mathrm{OKH}$ değerleri hesaplanırken aşağıdaki formüller kullanılmıştır.

$$
\begin{aligned}
& \mathrm{R}^{2}=\left(\mathrm{D}_{0}-\widehat{\mathrm{D}}\right) / \mathrm{D}_{0} \\
& \mathrm{D}_{0}=\sum_{\mathrm{i}=1}^{\mathrm{n}}\left(\mathrm{D}_{\mathrm{i}(\text { ölçüm })}-\mathrm{D}_{\text {ort }}\right)^{2} \\
& \widehat{\mathrm{D}}=\sum_{\mathrm{i}=1}^{\mathrm{n}}\left(\mathrm{D}_{\mathrm{i}(\text { ölçüm })}-\mathrm{D}_{\mathrm{i}(\text { tahmin })}\right)^{2} \\
& \mathrm{OKH}=\frac{1}{\mathrm{n}} \sum_{\mathrm{i}=\mathrm{n}}^{\mathrm{n}}\left(\mathrm{D}_{\mathrm{i} \text { (ölçüm })}-\mathrm{D}_{\mathrm{i}(\text { tahmin })}\right)^{2}
\end{aligned}
$$

Formülde, $\mathrm{n}$ gözlenmiş verilerin sayısı, $\mathrm{D}_{\mathrm{i}(\text { ölçüm) }} \mathrm{SYİ} \mathrm{yönteminden} \mathrm{hesaplanan} \mathrm{kuraklık,} \mathrm{D}_{\mathrm{i}(\operatorname{tahmin})}$ ANFIS yöntemi ile tahmin edilen kuraklık değeri ve $D_{\text {ort }}$ SYİ yönteminden elde edilen kuraklık değerlerinin ortalamasıdır. OKH'nin 0'a yakın değerler alması ve $\mathrm{R}^{2}$ 'nin 1 'e yakın değerler alması modelin iyi performans gösterdiği anlamına gelmektedir.

Karaisalı istasyonu için geliştirilen ANFIS modellerinin $\mathrm{R}^{2}$ ve $\mathrm{OKH}$ değerleri Tablo 4'te verilmiştir. 3, 6-, 9- ve 12- aylık periyotlar için elde edilen SYİ değerleri kullanılarak geliştirilen ANFIS modelleri değerlendirildiğinde, $0,72 \mathrm{R}^{2}$ değeri ile 9- aylık periyotta Mersin, Göksun ve Samandağ istasyonlarının verilerinin kullanıldığ ait saçılma diyagramları Şekil 4'te verilmiştir.

Tablo 4. Geliştirilen ANFIS modellerinin $R^{2}$ ve OKH değerleri

\begin{tabular}{cccccc}
\hline \multirow{2}{*}{ Periyot } & \multirow{2}{*}{ Model Girdileri } & \multicolumn{2}{c}{ Ĕgitim Seti } & \multicolumn{2}{c}{ Test Seti } \\
\cline { 3 - 5 } & & $\mathbf{R}^{\mathbf{2}}$ & $\mathbf{O K H}$ & $\mathbf{R}^{\mathbf{2}}$ & OKH \\
\hline 3 & Erdemli, Mersin, Göksun, Yumurtalık & 0,55 & 0,30 & 0,60 & 0,26 \\
\hline 6 & Mersin, Göksun, Samandağ, Kilis & 0,69 & 0,25 & 0,64 & 0,28 \\
\hline 9 & Mersin, Göksun, Samandağ & 0,71 & 0,24 & 0,72 & 0,24 \\
\hline 12 & Mersin, Erdemli, Kozan, Samandağ & 0,80 & 0,18 & 0,65 & 0,32 \\
\hline
\end{tabular}

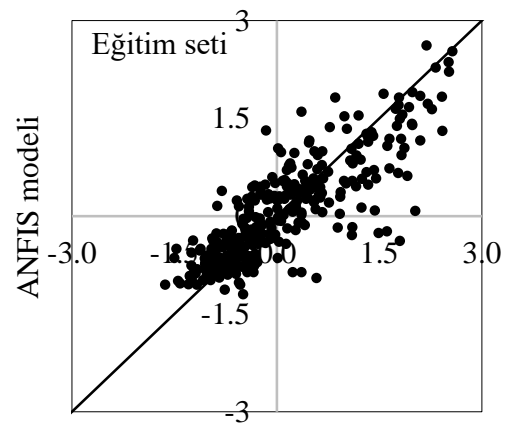

SYİ

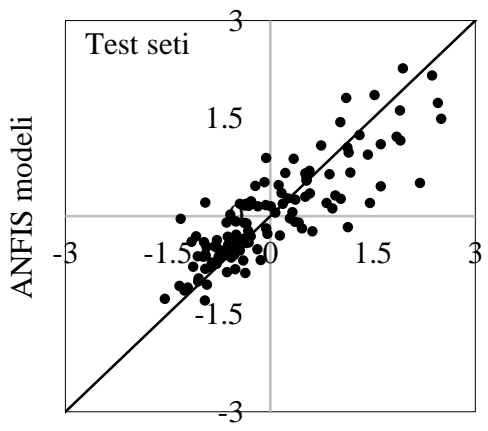

SYİ

Şekil 4. 9- aylık periyotta en uygun ANFIS modelinin sonuçları 
Şekil 5'te 9- aylık periyot için geliştirilen ANFIS modelinin zaman serisi verilmiştir. Zaman serisi incelendiğinde model sonuçları ile ölçülen değerlerin genel itibariyle birbiri ile uyum içinde olduğu görülmektedir.

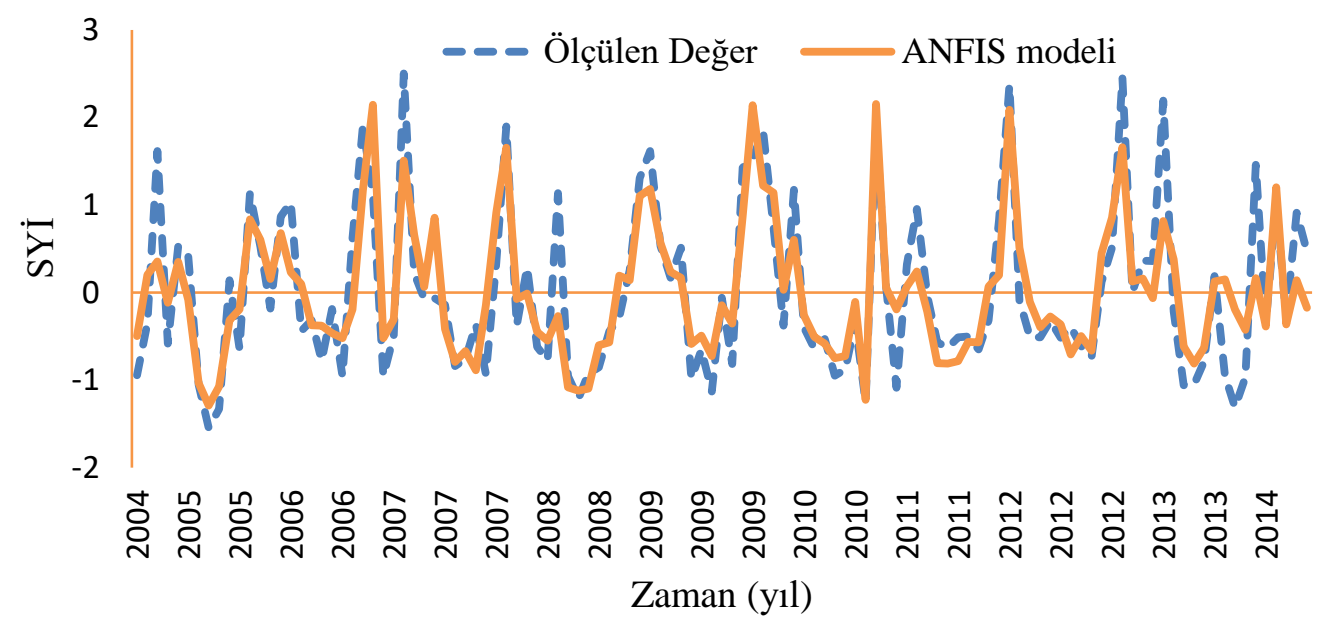

Şekil 5. 9- aylık periyotta en uygun ANFIS modelinin zaman serisi

\section{IV.SONUC}

Küresel ısınma, su kaynaklarında meydana gelen azalmalar, kullanılmakta olan su kaynaklarının bilinçsiz biçimde tüketilmesi kuraklığın oluşumuna zemin hazırlamaktadır. Geçmişte meydana gelen kurak dönemleri analiz etmek bir bölgede veya havzada meydana gelebilecek kuraklığın tahmin edilmesi için büyük önem taşımaktadır.

Bu çalışmada geçmişte kuraklık etkilerinin yüksek sıcaklıklar nedeniyle sık sık görüldüğü Çukurova Havzasında bulunan 11 adet meteoroloji gözlem istasyonunun 50 y1llık yağış verileri incelenerek kuraklık analizi yapılmıştır. Havzaya ait 1965-2014 yılları arasındaki yağış verileri kullanılarak 3-, 6-, 9- ve 12- aylık periyotlar için SYİ yöntemi kullanılarak kuraklık kategori olasılıkları belirlenmiştir. Bu olasılıklar incelendiğinde bölgenin genelinde çok şiddetli kurak dönemlerle karşılaşılmıştır. Şiddetli kuraklık en yoğun Kilis istasyonunda \% 2,1 kuraklık yüzdesi ile gözlenmiştir. Çok şiddetli kuraklık ise yalnızca Kilis ve Dörtyol istasyonlarında \% 0,1 oranında izlenmiş, diğer istasyonlarda ise çok şiddetli kurak dönemlere rastlanmamıştır. Havza geneli incelendiğinde özellikle 9 aylık periyotlarda hafif kurak dönemlere en fazla Mersin istasyonunda rastlanmıştır. Bölge genelinde hafif ve orta kurak dönemlere daha sık rastlanırken şiddetli ve çok şiddetli dönemlerin ise çok seyrek olduğu görülmüştür.

ANFIS modelleri geliştirilirken Karaisalı istasyonunun SYİ değerleri çıktı olarak kullanılmış, kalan diğer istasyonların SYİ değerleri ile farklı girdi kombinasyonları denenmiş ve en iyi performansı gösteren modeller belirlenmiştir. 3-, 6-, 9- ve 12- aylık SYİ değerleri için geliştirilen modeller incelendiğinde, 9- aylık periyot için geliştirilen modellerin genel olarak daha iyi performans gösterdiği görülmüştür. En düşük performans 3- aylık SYİ değerleri için geliştirilen modellerde elde edilmiştir. 9aylık periyot için Mersin, Göksun ve Samandağ istasyonlarının girdi olarak kullanıldığı model, geliştirilen modeller içerisinde en iyi performansa sahiptir. Sonuç olarak yapay zeka yöntemlerinden ANFIS yönteminin kuraklık tahmininde ve eksik veri durumunda kullanılabileceği görülmüştür.

\section{KAYNAKLAR}

[1] BMÇMS, Birleşmiş Milletler Çölleşme ile Mücadele Sözleşmesi, Ankara, Türkiye: Çevre Bakanlığı Yayınları, 1997. 
[2] Anonim, (2017, 24 [Online]. https://www.mgm.gov.tr/FILES/iklim/yayinlar/2014/Türkiye-Kuraklik-Degerlendirmesi-2014.pdf

[3] M. Özgürel, G. Pamuk, ve K. Topçuoğlu, "Palmer Kuraklık Şiddeti İndeksi ile Modellenmesi," II. Ulusal Hidroloji Kongresi, İstanbul, 1998, ss. 192-201.

[4] H. Hisdal ve L. M. Tallaksen, "Estimation of regional meteorological and hydrological drought characteristics," Journal of Hydrology, c. 281, ss. 230-247, 2003.

[5] B. Bonaccorso, I. Bordi, A. Cancelliere, G. Rossi ve A. Sutera, "Spatial variability of drought: an analysis of the SPI in Sicily," Water Resources Management, c. 17, ss. 273-296, 2003.

[6] T. Tonkaz ve M. Çetin, "Şanlıurfa'da kuraklık şiddetinin standardize yağış indeksi ile belirlenmesi ve kuraklık gidiş analizi," GAP IV. Tarım Kongresi, Şanlıurfa, Türkiye, 2005

[7] D. Deniz, “Türkiye'deki kuraklığın Standart Yağış İndeksi (SPI) ile incelenmesi,” Yüksek lisans tezi, Coğrafya Bölümü, Çanakkale Onsekiz Mart Üniversitesi, Çanakkale, Türkiye, 2009.

[8] A. Tanoğlu “Türkiye'nin kuraklık indisleri,” Türk Coğrafya Dergisi, s. 1, ss. 36-41, 1943.

[9] Ö. Köse ve A. Dorum, "Orta Anadolu kapalı havzası kuraklık parametrelerinin olasılık dağılımı," Turkish Journal of Engineering and Environmental Siciences, c. 26, ss. 85-93. 2002.

[10] D. Küçükyaman, "Kovada Gölü’nün hidrolojik ve meteorolojik kuraklık analizi," Yüksek lisans tezi, İnşaat Mühendsiliği Bölümü, Süleyman Demirel Üniversitesi, Isparta, Türkiye, 2010.

[11] G. Bacanlı, "Yapay Sinir Ağları ve Bulanık Mantık Yöntemleri ile Kuraklık Tahmini" yayınlanmamış rapor, Denizli, 2011.

[12] Anonim, (2018, 15 Şubat). [Online]. Erişim: https://www.turkcebilgi.com/Çukurova.

[13] T. B. Mckee, N. J. Doesken ve J. Kleist, "The Relationship of Drought Frequency and Duration to Time Scales," 8th Conference on Applied Climatology, Anaheim, CA, USA, 1993, ss. 179-184.

[14] E. Topçu, "L-Momentler ve Standart Yağış İndeksi (SYİ) Yardımıyla Seyhan Havzası Kuraklık Analizi," Yüksek Lisans Tezi, İnşaat Mühendisliği Bölümü, Çukurova Üniversitesi, Adana, Türkiye, 2013.

[15] S. Sırdaş, "Meteorolojik kuraklık modellemesi ve Türkiye uygulaması," Doktora tezi, İnşaat Mühendisliği Bölümü, İstanbul Teknik Üniversitesi, İstanbul, Türkiye, 2002.

[16] J. S. R. Jang, C. T. Sun ve E. Mizutani, Neuro-Fuzzy and Soft Computing, 1. Bask1, Upper Saddle River, United States of America: Prentice-Hall, Inc., 1997, s. 607.

[17] L. H. Tsoukalas ve R. E. Uhrig, Fuzzy and Neural Approaches In Engineering, 1. bask1. New York, USA: John Wiley\&Sons Inc., 1997.

[18] Ö. Demirel, A. Kakilli ve M. Tektaş, “ANFIS ve Arma Modelleri ile Elektrik Enerjisi Yük Tahmini," Gazi Üniversitesi Mühendislik Mimarlık Fakültesi Dergisi, c. 25, s. 3, ss. 601-610, 2010.

[19] K. Ak1 ve B. Karasulu, "Esnek Hesaplamada Sinirsel Bulanık Sinerjiyi Temel Alan Sistemler ve Yaklaşımlar Üzerine Bir İnceleme," Cumhuriyet Üniversitesi Fen Bilimleri Dergisi, c. 35, s. 2, ss. 54-86, 2014. 